Abdalrahaman, N., Mccomb, C., Foster, J.E., Lindsay, R.S., Drummond, R., McKay, G.A., Perry, C.G. and Ahmed, S.F. (2017) The relationship between adiposity, bone density and microarchitecture is maintained in young women irrespective of diabetes status. Clinical Endocrinology, 87(4), pp. 327-335. (doi:10.1111/cen.13410)

There may be differences between this version and the published version. You are advised to consult the publisher's version if you wish to cite from it.

This is the peer-reviewed version of the following article: Abdalrahaman, N., Mccomb, C., Foster, J.E., Lindsay, R.S., Drummond, R., McKay, G.A., Perry, C.G. and Ahmed, S.F. (2017) The relationship between adiposity, bone density and microarchitecture is maintained in young women irrespective of diabetes status. Clinical Endocrinology, 87(4), pp. 327-335, which has been published in final form at 10.1111/cen.13410. This article may be used for noncommercial purposes in accordance with Wiley Terms and Conditions for Self-Archiving.

http://eprints.gla.ac.uk/143417/

Deposited on: 03 July 2017 
DR NAIEMH ABDALRAHAMAN (Orcid ID : 0000-0003-4912-0321)

Article type $\quad: 1$ Original Article - UK, Europe

\section{The Relationship Between Adiposity, Bone Density And Microarchitecture Is Maintained In Young Women Irrespective Of Diabetes Status}

Abdalrahaman $\mathrm{N}^{1}$, McComb $\mathrm{C}^{2,3}$, Foster $\mathrm{JE}^{2,3}$, Lindsay $\mathrm{RS}^{3,4}$, Drummond $\mathrm{R}^{4}$, McKay $\mathrm{GA}^{4}$, Perry $\mathrm{CG}^{4}$, S Faisal Ahmed ${ }^{1}$

${ }^{1}$ Developmental Endocrinology Research Group, School of Medicine, University of Glasgow, Glasgow, UK

${ }^{2}$ Clinical Physics, NHS Greater Glasgow \& Clyde, Glasgow, UK

${ }^{3}$ BHF Glasgow Cardiovascular Research Centre, University of Glasgow, Glasgow, UK

${ }^{4}$ Stobhill Diabetes Centre, Stobhill Hospital, Glasgow, UK

\section{Address for Correspondence}

Professor S Faisal Ahmed MD FRCPCH

School of Medicine, University of Glasgow, Zone 1, Office Block, RHC \& QEUH Campus

1345 Govan Road, Glasgow, G51 4TF, UK. Tel 0141-451 5841, Fax 01412012215

faisal.ahmed@glasgow.ac.uk

This article has been accepted for publication and undergone full peer review but has not been through the copyediting, typesetting, pagination and proofreading process, which may lead to differences between this version and the Version of Record. Please cite this article as doi: 10.1111/cen.13410

This article is protected by copyright. All rights reserved. 
Short Title: Adiposity \& bone health

Keywords: body composition; bone marrow adipose tissue; BMD; DXA; MRI

\section{Abstract}

Background: The relationship between bone health and adiposity and how it may be affected in people with chronic metabolic conditions is complex.

Methods: 17 women with Type 1 diabetes mellitus (T1DM) and 9 age-matched healthy women with a median age of 22.6 yrs (range, $17.4,23.8$ ) were studied by $3 T-M R I$ and MR spectroscopy to assess abdominal adiposity, tibial bone microarchitecture and vertebral bone marrow adiposity. Additional measures included DXA-based assessments of total body (TB), femoral neck (FN) and lumbar spine (LS) bone mineral density (BMD) and fat mass (FM).

Results: Although women with T1DM had similar BMI and bone marrow adiposity to the controls, they had higher visceral and subcutaneous adiposity on MRI $(p<0.05)$ and total body FM by DXA $(p=0.03)$. Overall, in the whole cohort, a clear inverse association was evident between bone marrow adiposity and BMD at all sites $(p<0.05)$. These associations remained significant after adjusting for age, BMI, FM, and abdominal adiposity. In addition, visceral adiposity, but not subcutaneous adiposity, showed a positive association with bone marrow adiposity $(r, 0.4, p=0.03)$, and a negative association with total body $B M D(r, 0.5$, $\mathrm{p}=0.02$ ). Apparent trabecular separation as assessed by MRI showed an inverse association to total body BMD by DXA $(r,-0.4, p=0.04)$.

Conclusion: Irrespective of the presence of an underlying metabolic condition, young women display a negative relationship between MRI-measured bone marrow adiposity and

This article is protected by copyright. All rights reserved. 
DXA-based assessment of bone mineral density. Furthermore, an association between bone marrow adiposity and visceral adiposity supports the notion of a common origin of these two fat depots.

\section{Background}

Type 1 diabetes mellitus (T1DM) is a chronic metabolic disorder that is often associated with an alteration in the quantity and distribution of adipose tissue (1). In addition, people of all ages with T1DM are at a higher risk of fractures (2-4). Although the underlying pathophysiology of diabetic osteopathy is complex and multifactorial (5), there is a growing body of evidence that suggests that the interplay between fat and bone may generally play an important role in conferring skeletal fragility (6). Previous studies have reported an inverse association of bone marrow adiposity (BMA) with bone mineral density (BMD) in elderly people with osteoporosis and other metabolic conditions $(7,8)$. Several clinical and experimental studies indicate that adipose tissue itself is not functionally uniform, and different adipose depots have distinctive characteristics including adipocytokine production (9) with visceral adipose tissue (VAT) playing an important role in the maintence of bone health $(10,11)$. Thorough, in vivo assessment of adiposity at multiple sites, including abdominal, total body and bone marrow, requires several methods of imaging and hitherto this has rarely been performed in humans (11). There is an increasing realisation that a comprehensive assessment of bone requires an assessment of bone microarchitecture as well as bone densitometry (13). Metabolic conditions that may affect bone health, such as diabetes, are also associated with marked alterations in body composition, adiposity and bone marrow adiposity (12). Our objective was to utilise a wide range of imaging tools to evaluate adiposity at several sites and assess its relationship to quantifiable, imaging-based markers of bone health in young women with and without T1DM. The underlying hypothesis was that the inverse association between adiposity and bone health exists irrespective of the

This article is protected by copyright. All rights reserved. 
body compartment and mode of assessment of bone health. By performing a multimodality assessment of bone health and adiposity this study has also provided greater mechanistic insights into the link between bone and fat as well as the pathophysiology of diabetic osteopathy.

\section{Methods}

\section{Population}

Between January and July 2014, 9 healthy women and 17 women with T1DM between the ages of 17 and 34 years participated in a study of bone health and adiposity. Exclusion criteria included the presence of metallic implants and pacemakers, active or planned pregnancy or lactation, kidney disease, chronic use of drugs that are known to affect bone health and other chronic diseases that are known to be associated with an increased risk of fractures. Information on personal health and lifestyle habits, including cigarette smoking, alcohol consumption, current medication, use of vitamins or calcium, age at menarche, use of oral contraceptives, hours of weight-bearing physical activity per week, history of fractures and a family history of early osteoporosis was also collected. In the women with T1DM, information on age of diagnosis, disease duration, insulin therapy and presence of microvascular complications was obtained from the case records. The study protocol was approved by the national research ethics service and all participants provided written informed consent.

\section{MicroMRI}

MRI images of the proximal tibia with a resolution of $0.3 \mathrm{~mm} \times 0.3 \mathrm{~mm} \times 0.3 \mathrm{~mm}$ were acquired with a 3T MRI scanner (Siemens Verio, Erlangen Germany) using a transmit/receive extremity coil which was suitable for knee imaging. The method used has been described previously $(1,13)$ but briefly, the images were acquired from the right

This article is protected by copyright. All rights reserved. 
proximal tibia using the epiphyseal growth plate as a reference, with the first slice positioned immediately distal and parallel to the growth plate and subsequent slices positioned distally along the tibia. The pulse sequence was a fully balanced steady state free precession (bSSFP), and the acquisition was 3D. Standardized analysis was performed using the slice that was located at the insertion point of the patellar ligament. The images were coded and analysed blindly using software written in IDL (Research Systems Inc, Boulder, CO) to obtain measures for apparent bone volume to total volume ratio (appBV/TV), apparent trabecular number (appTbN), apparent trabecular thickness (appTbTh) and apparent trabecular separation (appTbSp). Validation of the software was performed using a custommade phantom as described previously (13).

\section{MR Spectroscopy (MRS)}

1H-MRS was performed using a 6-channel body array (anterior) and a 12-channel spine coil (posterior). Spectra were obtained from a $20 \mathrm{~mm} \times 20 \mathrm{~mm} \times 20 \mathrm{~mm}$ volume within the vertebral body of L3, using a method which has been described previously $(1,13)$. A PRESS sequence with no water suppression was used with the following parameters: $T R=$ $2000 \mathrm{~ms}, \mathrm{TE}=30 \mathrm{~ms}$, no. of averages $=80$, total scan time $=4$ minutes. Analysis was performed following fitting of the spectrum in the time domain using a nonlinear leastsquares algorithm, AMARES (14) in the Java-based magnetic resonance user interface (jMRUI) software package (15). The area under the water peak and lipid peak were obtained and used to calculate the lipid to water ratio (LWR) and percentage fat fraction (\%FF) as a measure of bone marrow adiposity (BMA) (16) using the following equation:

$$
\% F F=\left(\frac{L W R}{L W R+1}\right) \times 100
$$

MRI of abdominal fat

This article is protected by copyright. All rights reserved. 
Of the participants who had MRS scans, approval was also obtained to simultaneously assess abdominal fat using the 6-channel body array and the 12-channel spine coil. A T1 weighted turbo-spin-echo sequence was used to acquire 5 axial slices at the level of L3 with a $4 \mathrm{~mm}$ slice thickness using the following parameters: (TR) Repetition Time 300ms, (TE) Echo Time $11 \mathrm{~ms}$, (TA) Acquisition Time 17.2s, matrix size $=288 \times 320$, with $255 \times 340 \mathrm{~mm}$ field of view. The images were analysed with Slice-O-matic ${ }^{\mathrm{TM}}$ (version 4.3, Tomovision, Canada) for semi-automatic measurement of cross-sectional area (CSA), subcutaneous adipose tissue, (SAT), visceral adipose tissue (VAT) and total adipose tissue (TAT) (Fig. 1).

\section{Dual Energy X-ray Absorptiometry (DXA)}

DXA of the total body (TB), lumbar spine at L2-L4 (LS) and femoral neck (FN) was performed by a Lunar Prodigy Scanner (GE Medical Systems, Waukesha, Wisconsin, USA). Outputs included bone area $\left(\mathrm{cm}^{2}\right)$, BMC $(\mathrm{g})$ and mean areal BMD $\left(\mathrm{g} / \mathrm{cm}^{2}\right)$ and these data were used to calculate standard deviation scores (SDS) of TB, LS and FN BMD and LS bone mineral apparent density (BMAD) (17). DXA was also used to measure fat mass and these data were used to calculate percentage FM and FM SDS to correct for age and sex.

\section{Statistical Analysis}

Data analysis was performed using Minitab 17, Minitab Inc, State College, PA. All data were described as medians and ranges; comparison between the cases of T1DM and healthy women was performed by the Mann-Whitney $U$ test for continuous variables and by the Chi Squared test for categorical variables. Spearman correlation analysis was used to assess the univariate relationship between continuous variables and statistical significance was set at $p<0.05$. Multivariable linear regression was performed to examine associations of vertebral BMA, BMD and visceral adiposity. BMA, age, height, weight, and VAT were 
selected for the regression model because of their close correlation to BMD. Multivariate standard least squares regression modeling was performed to control for age, BMI, BMD, and VAT.

\section{Results}

\section{Study Participants}

There were no significant demographic or anthropometric differences between the cases and controls (Table 1). The median age of the 17 women with T1DM was $23.7 \mathrm{yrs}(17.4,34)$, and the median age at diagnosis was $10.1 \mathrm{yrs}(4.8,14.8)$ with a median duration of diabetes of 13.6 yrs $(6.8,26.5)$. In the T1DM cohort, $5(29 \%)$ reported a history of traumatic fractures and in 3 , the fractures had occurred before the diagnosis of diabetes. No fractures were reported in the healthy women group and none of the participants were on routine vitamin supplementation. Of the 17 cases, $9(50 \%)$ had retinopathy of which 8 had background retinopathy alone, 2 (7\%) were being treated for hypertension, and 3 (18\%) had microalbuminuria. One of the cases had stable Crohn's disease over the study period requiring only sulfasalazine therapy for three years prior to the baseline assessment. At the time of the study the women with T1DM were on a median insulin dose of $2.5 \mathrm{IU} / \mathrm{kg} / \mathrm{d}(1.2$, 3.7) and the median $\mathrm{HbA} 1 \mathrm{c}$ was $75 \mathrm{mmol} / \mathrm{mol}(51,118)$.

\section{Measures of Adiposity}

Abdominal adiposity parameters measured by MRI and including CSA, SCAT, VAT and TAT, were higher in the T1DM cases compared to the healthy women (Table 2). Additionally, women with T1DM had higher DXA-measured TB FM SDS ( $p=0.03)$. However, median vertebral BMA as assessed by measuring percentage fat fraction at L3 was similar in the two groups of women. VAT was positively associated with increasing vertebral BMA

This article is protected by copyright. All rights reserved. 
FF (\%) for all participants $(0.42,0.03)$, although when the participants were sub-divided into healthy women and those with T1DM the association remained for the healthy women $(0.72$, $0.02)$ but not for those with $\operatorname{T1DM}(0.31,0.22)$. However other abdominal measures of SCAT and TAT did not show an association with vertebral BMA FF (\%) (Suppl Table I).

\section{Measures of Bone Mineral Status \& Microarchitecture}

No significant difference in DXA or MRI-based parameters was evident between women with or without T1DM (Table 2). In the whole cohort of participants, body weight showed a clear association to DXA-BMD but not to MRI-measured bone microarchitecture (Fig.2). On the other hand, age showed a clear association to appTbN and appTbSp but not BMD over the age range studied $(r,-0.61, p=0.001$ and $r, 0.45, p=0.02$, respectively) and the extent of this association was not influenced by the coexistence of DM (Fig.3). On assessing the association between age and appTbN for the cases and controls separately the association remained significant for the former $(r,-0.5, p=0.04$ and $r,-0.54, p=0.09$. repectively) (Fig. 3). Although the association between DXA measured TB-BMD, FN-BMD and LS-BMD was strong as expected, the association of these DXA parameters with MRI-based microarchitectural parameters was weak and not significant (Supplementary Table II).

\section{Correlation between Markers of Adiposity \& Bone Mineral Status \& Microarchitecture}

MRI-based markers of bone microarchitecture did not show any significant association to vertebral BMA. However, vertebral BMA showed a negative association to several measures of DXA-based markers of bone mineral status including TB-BMD $(r,-0.54$, $\mathrm{p}=0.005)$, LS-BMD ( $r,-0.40, \mathrm{p}=0.04)$ and FN-BMD ( $r,-0.44, \mathrm{p}=0.03)$ (Table 3). Vertebral BMA was a significant determinant of BMD $(p<0.05)$ in all models when its relationship was assessed in a regression model with age, BMI, VBMA, TAT, VAT. Amongst the MRI-based 
markers of abdominal adiposity and DXA-based markers of bone mineral status, VAT and TB-BMD SDS were the sole parameters which showed a clear association $(r,-0.46, p=0.02)$ and this association did not seem to be dependent on whether the subject had diabetes or not (Fig. 4). Given that there is an association between VAT and TB- BMD SDS as well as VAT and vertebral BMA, adjustment for VAT was performed by multivariate analysis and an association between vertebral BMA and TB-BMD was still evident $(p=0.04)$.

\section{Discussion}

To our knowledge, this is the first study to characterize relationships between measures of adiposity with DXA and MRI-based measures of bone parameters in young women. The study was limited by its small size. However, by including a group of women with T1DM within our study cohort, we were also able to explore relationships over a wider range of adiposity.

Since osteoblasts and adipocytes share the bone marrow derived mesenchymal stem cells (MSC) as a common precursor $(18,19)$, it is hypothesized that an increase in adipogenesis may impair bone integrity through reducing osteoblastogenesis (19). The study clearly showed that VAT and BMA are negative predictors of BMD. The inverse relationship between DXA-based measures of bone parameters at multiple skeletal sites and bone marrow adiposity has been reported in a range of people across the age span as well as those with anorexia nervosa, on glucocorticoid therapy and other osteoporotic conditions (20-22). Rodent models of acute T1DM are also associated with higher BMA (23) and although stable T1DM may not be associated with raised BMA (1), in people with diabetes, BMA may be inversely related to BMD (24). The current findings provide additional support for this inverse relationship and also confirm that this relationship is found in health and disease. Whilst it is plausible that these relationships may be altered in people with diabetes,

This article is protected by copyright. All rights reserved. 
the current study did not show that the relationship, itself is altered. It is possible, however, that this relationship may vary from one pathological condition to another (13) and this requires further exploration. Recent studies also suggest that unsaturated bone marrow lipids may be more strongly associated than overall bone marrow adiposity with fragility fractures in diabetes $(8,25)$ and there is a need to explore this further.

In the present study, we observed an inverse relationship between BMA and BMD in nonanatomically-matched regions such as the spine for BMA and femoral and total body for BMD, as well as in anatomically-matched region such as the spine. Therefore, it is reasonable to assume that both MSC differentiation at a local level and hormonal factors at a systemic level contribute to the observed inverse relationship between BMA and BMD. These observations will be further

strengthened by an assessment of bone microarchitecture and BMA at other skeletal sites in the future. MRI with its ability to study microarchitecture as well as BMA promises to be a useful imaging modality for studying these relationships in larger cohorts. A thorough investigation of adiposity and bone health as performed by us may, therefore, be vital when new therapies that treat osteoporosis at both the MSC level and systemic level are explored.

The role of VAT in influencing bone development has not been clearly elucidated; previous studies have shown an inconsistent association between body fat and bone measures(2632). These studies were limited by the use of DXA, which in the past has been unable to distinguish VAT from SAT. In our study, despite a high level of correlation between the DXA and MRI-based parameters of adiposity, we found differences in their relationship to BMA and the bone parameters. Our data are consistent with other reports $(31,33)$ that did not

This article is protected by copyright. All rights reserved. 
show any association between adiposity, as assessed by DXA, and BMD. In contrast, other studies have reported that visceral fat may have a negative association with bone mineral status and correlates inversely with BMD and bone structure (10, 34, 35). However, in our study we did not find this association with bone microarchitecture. Consistent with our findings, Bredella et al. (10) also concluded that both BMA and VAT may have a detrimental effect on BMD.

Recent studies including the current study have (36) reported a deficit in bone microarchitecture, as assessed by MRI, in people with T1DM and especially those who have some evidence of a vasculopathy $(1,36)$. In contrast, such a consistent abnormality in DXAbased bone parameters in T1DM is rarely described (5). A discrepancy between DXA and an assessment of trabecular bone microarchitecture as reported in the current study, reinforces the point that the two modalities, MRI and DXA, may not necessarily provide the same information about bone health but may complement each other. Whilst, there are other techniques such as high resolution $\mathrm{PQCT}$ which can also provide information on microarchitecture at specific sites, MRI has the added advantage of being able to assess bone marrow adiposity .

In summary, visceral adipose tissue and bone marrow adiposity are closely linked to each other and show a negative association to BMD in young women with diabetes as well as healthy women. A comprehensive assessment of bone health may require an approach that combines conventional assessment by DXA with an assessment of bone marrow adiposity and microarchitecture by MRI.

This article is protected by copyright. All rights reserved. 


\section{Acknowledgements}

We would like to acknowledge the support of the Medical Fund of the University of Glasgow. We would also like to thank Tracey Steedman, Kirsten Lanaghan, Heather Boylan, Alison Frood and Evonne McLennan for their assistance with image acquisition. NA is supported by the Government of Libya. CM is supported through the Scottish Academic Health Sciences Collaboration. NA recruited the cases, performed the study, analysed the data and wrote the manuscript, CM performed the study, analysed the data and wrote the manuscript, JF revised the manuscript, RSL designed the study, recruited the cases and revised the manuscript, RD, GM, CP recruited the cases and revised the manuscript. SFA conceived and designed the study, analysed the data, wrote the manuscript and acts as the guarantor.

\section{References}

1. Abdalrahaman $\mathrm{N}, \mathrm{McComb} \mathrm{C}$, Foster $\mathrm{J}$ et al. Deficits in trabecular bone microarchitecture in young women with Type 1 Diabetes Mellitus. J Bone Miner Res. 2015;30:1386-93.

2. Vestergaard P. Discrepancies in bone mineral density and fracture risk in patients with type 1 and type 2 diabetes - a meta-analysis. Osteoporosis Int. 2007;18:427-44.

3. Hothersall EJ, Livingstone SJ, Looker HC et al. Contemporary risk of hip fracture in type 1 and type 2 diabetes: a national registry study from Scotland. J Bone Miner Res. 2014;29: 1054-60.

4. Weber DR, Haynes K, Leonard MB, Willi SM, Denburg MR. Type 1 diabetes is associated with an increased risk of fracture across the life span: a population-based cohort study using the health improvement network (THIN). Diab Care. 2015;38:1913-20.

5. Abdalrahman N, Chen SC, Wang JR, Ahmed SF. An update on diabetes related skeletal fragility. Exp Rev Endocrinol Metab. 2015;10:193-210.

6. Kremer R, Gilsanz V. Fat and bone: an odd couple. Front Endocrinol. 2015;6:190.

7. Schorr M, Dichtel LE, Gerweck AV, Torriani M, Miller KK, Bredella MA. Body composition predictors of skeletal integrity in obesity. Skeletal Radiol. 2016;45:813-9.

8. Patsch JM, Li X, Baum T et al. Bone marrow fat composition as a novel imaging biomarker in postmenopausal women with prevalent fragility fractures. $J$ Bone Miner

This article is protected by copyright. All rights reserved. 
Res. 2013;28:1721-8.

9. Fontana L, Eagon JC, Trujillo ME, Scherer PE, Klein S. Visceral fat adipokine secretion is associated with systemic inflammation in obese humans. Diabetes. 2007;56:1010-3.

10. Bredella MA, Torriani M, Ghomi RH et al. Vertebral bone marrow fat is positively associated with visceral fat and inversely associated with IGF-1 in obese women. Obesity 2011;19:49-53.

11. Mostoufi-Moab S, Magland J, Isaacoff EJ et al. Adverse fat depots and marrow adiposity are associated with skeletal deficits and insulin resistance in long-term survivors of pediatric hematopoietic stem cell transplantation. J Bone Miner Res. 2015;30:1657-66.

12. Cordes C, Baum T, Dieckmeyer M et al. MR-Based Assessment of Bone Marrow Fat in Osteoporosis, Diabetes, and Obesity. Front Endocrinol. 2016;7:74.

13. McComb C, Harpur A, Yacoubian C et al. MRI-based abnormalities in young adults at risk of adverse bone health due to childhood-onset metabolic \& endocrine conditions. Clin Endocrinol. 2014;80:811-7.

14. Vanhamme L, van den Boogaart A, Van Huffel S. Improved method for accurate and efficient quantification of MRS data with use of prior knowledge. J Magn Reson. 1997;129:35-43.

15. Naressi A, Couturier C, Devos JM et al. Java-based graphical user interface for the MRUI quantitation package. Magma (New York, NY). 2001;12:141-52.

16. Schellinger D, Lin CS, Lim J, Hatipoglu HG, Pezzullo JC, Singer AJ. Bone marrow fat and bone mineral density on proton MR spectroscopy and dual-energy X-ray absorptiometry: their ratio as a new indicator of bone weakening. AJR Am J Roentgenol. 2004;183:1761-5.

17. Carter DR, Bouxsein ML, Marcus R. New approaches for interpreting projected bone densitometry data. J Bone Miner Res. 1992;7:137-45.

18. Gimble JM, Robinson CE, Wu X, Kelly KA. The function of adipocytes in the bone marrow stroma: an update. Bone. 1996;19:421-8.

19. Pino AM, Rosen CJ, Rodriguez JP. In osteoporosis, differentiation of mesenchymal stem cells (MSCs) improves bone marrow adipogenesis. Biol Res. 2012;45:279-87.

20. Bredella MA, Fazeli PK, Daley SM, Miller KK, Rosen CJ, Klibanski A, et al. Marrow fat composition in anorexia nervosa. Bone. 2014;66:199-204.

21. Shen W, Chen J, Punyanitya M, Shapses S, Heshka S, Heymsfield SB. MRImeasured bone marrow adipose tissue is inversely related to DXA-measured bone mineral in Caucasian women. Osteoporosis Int. 2007;18:641-7.

22. Griffith JF, Yeung DKW, Antonio GE et al. Vertebral bone mineral density, marrow perfusion, and fat content in healthy men and men with osteoporosis: Dynamic

This article is protected by copyright. All rights reserved. 
contrast-enhanced MR imaging and spectroscopy. Radiol. 2005;236:945-51.

23. Botolin S, McCabe LR. Bone loss and increased bone adiposity in spontaneous and pharmacologically induced diabetic mice. Endocrinol 2007;148:198-205.

24. Slade JM, Coe LM, Meyer RA, McCabe LR. Human bone marrow adiposity is linked with serum lipid levels not T1-diabetes. J Diabetes Complications. 2012;26:1-9.

25. Baum T, Yap SP, Karampinos DC et al. Does vertebral bone marrow fat content correlate with abdominal adipose tissue, lumbar spine bone mineral density, and blood biomarkers in women with type 2 diabetes mellitus? J Magn Reson Imaging. 2012;35:117-24.

26. Janicka A, Wren TA, Sanchez MM et al. Fat mass is not beneficial to bone in adolescents and young adults. J Clin Endocrinol Metab 2007;92:143-7.

27. Jiang $Y$, Zhang $Y$, Jin M, Gu Z, Pei Y, Meng P. Aged-related changes in body composition and association between body composition with bone mass density by body mass index in Chinese Han men over 50-year-old. PloS One. 2015;10:e0130400.

28. Liu PY, llich JZ, Brummel-Smith K, Ghosh S. New insight into fat, muscle and bone relationship in women: determining the threshold at which body fat assumes negative relationship with bone mineral density. Int J Prev Med 2014;5:1452-63.

29. Ho-Pham LT, Nguyen ND, Lai TQ, Nguyen TV. Contributions of lean mass and fat mass to bone mineral density: a study in postmenopausal women. BMC Musculoskelet Disord. 2010;11:59.

30. Weiler HA, Janzen L, Green K, Grabowski J, Seshia MM, Yuen KC. Percent body fat and bone mass in healthy Canadian females 10 to 19 years of age. Bone. 2000;27:203-7.

31. Joshi A, Varthakavi P, Chadha M, Bhagwat N. A study of bone mineral density and its determinants in type 1 diabetes mellitus. J Osteoporos. 2013;2013:397814.

32. Edwards $\mathrm{MH}$, Ward KA, Ntani G et al. Lean mass and fat mass have differing associations with bone microarchitecture assessed by high resolution peripheral quantitative computed tomography in men and women from the Hertfordshire Cohort Study. Bone. 2015;81:145-51.

33. Ingberg CM, Palmer M, Aman J, Arvidsson B, Schvarcz E, Berne C. Body composition and bone mineral density in long-standing type 1 diabetes. $J$ Intern Med. 2004;255:392-8.

34. Lv S, Zhang A, Di W, Sheng Y, Cheng P, Qi H, et al. Assessment of fat distribution and bone quality with trabecular bone score (TBS) in healthy Chinese men. Sci Rep 2016;6: 24935.

35. Gilsanz V, Chalfant J, Mo AO, Lee DC, Dorey FJ, Mittelman SD. Reciprocal relations of subcutaneous and visceral fat to bone structure and strength. J Clin Endocrinol Metab 2009;94:3387-93.

This article is protected by copyright. All rights reserved. 
36. Shanbhogue VV, Hansen S, Frost M et al. Bone geometry, volumetric density, microarchitecture, and estimated bone strength assessed by hr-pqct in adult patients with type 1 diabetes mellitus. J Bone Miner Res. 2015;30:2188-99.

\section{Legend}

Fig 1. Representative MR Image through axial slice of abdomen at L3 vertebrae showing T1-weighted images with subcutaneous adipose tissue (SAT) and visceral adipose tissue (VAT) in a woman with Type 1 Diabetes (A) and in a healthy woman (B).

Fig 2. The relationship between vertebral bone marrow adiposity expressed as fat fraction (FF \%) as assessed by MRS and abdominal adipose tissue as assessed by MRI. Cross sectional area (CSA) (A), subcutaneous adipose tissue (SCAT) (B), visceral adipose tissue (VAT) (C) and total adipose tissue (TAT) (D) in women with Type 1 Diabetes (filled circles, solid regression line) and in healthy women (open circles, broken regression line). The correlation $(r)$ and its $p$-value $(p)$ are for the combined group of women.

Fig 3. The relationship between parameters of bone health as assessed by MRI and DXA and age or body weight in women with Type 1 Diabetes (filled circles, solid regression line) and in healthy women (open circles, broken regression line). The relationship of MRI-based apparent trabecular number $(\mathrm{TbN})$ with age $(\mathrm{A})$ and body weight $(\mathrm{B})$ and the relationship of DXA-based total body bone mineral density (TB-BMD) with age (C) and body weight (D). Regression lines have been added to each plot, solid line for the cases and the broken line for the controls. The correlation $(r)$ and its $p$-value $(p)$ are for the combined group of women.

Fig 4. The relationship between visceral adipose tissue (VAT) as assessed by MRI and TBBMD SDS in women with Type 1 Diabetes (filled circles, solid regression line) and in healthy women (open circles, broken regression line). The correlation ( $r$ ) and its $p$-value $(p)$ are for the combined group of women.

This article is protected by copyright. All rights reserved. 


\begin{tabular}{|c|c|c|c|}
\hline & Type 1 Diabetes Mellitus $(n, 17)$ & Healthy Women $(n, 9)$ & $p$ \\
\hline Age (years) & $\begin{array}{c}23.7 \\
(17.4,34)\end{array}$ & $\begin{array}{c}21.6 \\
(20,23.8)\end{array}$ & 0.1 \\
\hline $\mathrm{Ht}(\mathrm{cm})$ & $\begin{array}{c}163.6 \\
(160.5,175.5)\end{array}$ & $\begin{array}{c}166.2 \\
(159.2,183)\end{array}$ & 0.5 \\
\hline $\mathrm{Ht}$ SDS & $\begin{array}{c}-0.03 \\
(-1.5,1.9)\end{array}$ & $\begin{array}{c}0.4 \\
(-0.7,3.2)\end{array}$ & 0.5 \\
\hline Wt (kg) & $\begin{array}{c}68.8 \\
(50.2,91.5)\end{array}$ & $\begin{array}{c}63.8 \\
(54.4,76.5)\end{array}$ & 0.5 \\
\hline Wt SDS & $\begin{array}{c}1.2 \\
(-1,2.9)\end{array}$ & $\begin{array}{c}0.7 \\
(-0.4,2.9)\end{array}$ & 0.5 \\
\hline BMI & $\begin{array}{c}24.4 \\
(18.7,31.6)\end{array}$ & $\begin{array}{c}22.6 \\
(19.6,28.0)\end{array}$ & 0.1 \\
\hline BMI SDS & $\begin{array}{c}0.82 \\
(-1.4,2.4)\end{array}$ & $\begin{array}{c}0.2 \\
(-0.9,1.7)\end{array}$ & 0.1 \\
\hline Cigarette smoker (n) & 4 & 0 & 0.2 \\
\hline Regular alcohol consumption (n) & 13 & 7 & 1 \\
\hline Age at Menarche (years) & $\begin{array}{c}13 \\
(10,17.50)\end{array}$ & $\begin{array}{c}12 \\
(11,15)\end{array}$ & 0.9 \\
\hline Previous pregnancy (n) & 3 & 0 & 0.2 \\
\hline Oral contraceptive use (n) & 10 & 9 & 0.4 \\
\hline
\end{tabular}

This article is protected by copyright. All rights reserved. 
Table 1. Clinical characteristic of study participants.

\section{Type 1 Diabetes Mellitus}

$$
(\mathrm{n}, 17 \text { ) }
$$

\section{MRI - Abdominal adiposity}

$$
\text { CSA }\left(\mathrm{mm}^{3}\right)
$$$$
\operatorname{SCAT}\left(\mathrm{mm}^{3}\right)
$$$$
\operatorname{VAT}\left(\mathrm{mm}^{3}\right)
$$$$
\operatorname{TAT}\left(\mathrm{mm}^{3}\right)
$$

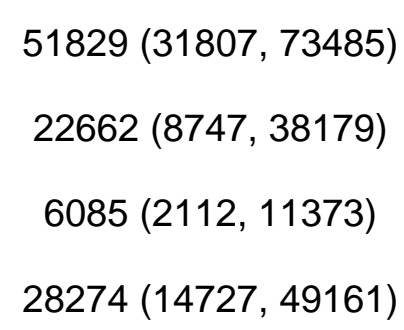

$$
(\mathrm{n}, 9)
$$

\section{DXA - Fat Mass}

TB-FM (kg)

TB-fat mass SDS

$\begin{array}{cc}39761(32004,55860) & 0.04 \\ 12529(8078,25829) & 0.02 \\ 3460(1864,7134) & \mathbf{0 . 0 0 4} \\ 16251(10343,32963) & \mathbf{0 . 0 0 7}\end{array}$

$39761(32004,55860) \quad 0.04$

0.02

0.007 
MRS - Bone Marrow Adiposity

L3 fat fraction (\%)

$26.9(17.2,58.5)$

$25.2(8.3,35.1)$

0.5

MRI - Bone microarchitecture

App BV/TV

$0.29(0.25,0.38)$

$0.32(0.27,0.42)$

0.1

App TbN (mm-1)

$0.26(0.20,0.32)$

$0.27(0.24,0.31)$

0.2

App TbSp (mm)

$2.65(2.06,3.38)$

$2.52(1.94,2.79)$

0.08

App ThTh (mm)

$1.17(0.95,1.46)$

$1.19(1.00,1.52)$

0.7

\section{DXA - Bone Mineral Density}

TB BMC (g)

TB BMD $\left(\mathrm{g} / \mathrm{cm}^{2}\right)$

TB BMD SDS

LS BMC (g)

LS BMD $\left(\mathrm{g} / \mathrm{cm}^{2}\right)$

LS BMD SDS
2504 (1669, 2967)

$$
1.1(1,1.2)
$$$$
-0.2(-1.1,1.5)
$$

$49.8(26.6,60.8)$

$1.18(0.82,1.39)$

$-0.1(-3.1,1.6)$
$2636(2147,3)$

0.3

$1.1(1,1.3)$

0.5

$0.4(-1.2,2.0)$

0.3

$56.7(38.2,66.9)$

0.2

$1.24(0.99,1.42)$

0.8

$0.4(-1.7,1.8)$

0.8

This article is protected by copyright. All rights reserved. 
Table 2. Markers of adiposity and bone health as assessed by micro MRI, DXA and MRS in women with T1DM and in health women. CSA- cross-sectional area of adipose tissue; SCAT - subcutaneous adipose tissue; VAT- visceral adipose tissue; TAT - total adipose tissue; TB FM- total body fat mass; TB BMC; total body bone mineral content; TB BMD; total body bone mineral density; LS BMC- lumbar spine bone mineral content; LS BMD- lumbar spine bone mineral density; LS BMAD- lumbar spine bone mineral apparent density; FN-BMC; femoral neck bone mineral content; FN-BMD; femoral neck bone mineral density; AppBV/TV - apparent bone volume/total volume; AppTb.N - apparent trabecular number; AppTbSp - apparent trabecular separation; AppTbTh - apparent trabecular thickness; BMA- bone marrow adiposity; FF\% fat fraction.

This article is protected by copyright. All rights reserved. 


\begin{tabular}{|c|c|c|c|c|c|c|c|}
\hline Markers of Adiposity & CSA & SCAT & VAT & TAT & TB FM & TB FM SDS & Vertebral BMA \\
\hline \multicolumn{8}{|l|}{ Markers of Bone } \\
\hline TB BMD $\left(\mathrm{g} / \mathrm{cm}^{2}\right)$ & $0.02, p=0.9$ & $-0.05, p=0.8$ & $-0.18, p=0.4$ & $-0.14, p=0.5$ & $0.06, p=0.8$ & $0.01, p=0.6$ & $-0.54, p=0.005$ \\
\hline TB BMD SDS & $-0.21, p=0.3$ & $-0.26, p=0.2$ & $-0.46, p=0.02$ & $-0.38, p=0.1$ & $-0.18, p=0.4$ & $-0.20, p=0.4$ & $0.49, p=0.013$ \\
\hline TB BMC $(\mathrm{g})$ & $0.11, p=0.6$ & $-0.05, P=0.8$ & $-0.18, p=0.4$ & $-0.12, p=0.6$ & $0.21, p=0.3$ & $0.19, p=0.4$ & $-0.28, p=0.2$ \\
\hline LS BMD $\left(\mathrm{g} / \mathrm{cm}^{2}\right)$ & $0.14, p=0.5$ & $0.08, p=0.7$ & $0.04, p=0.8$ & $0.00, p=0.9$ & $0.13, p=0.5$ & $0.16, p=0.5$ & $-0.40, p=0.04$ \\
\hline LS BMD SDS & $0.11, p=0.6$ & $0.06, p=0.8$ & $0.02, p=0.9$ & $-0.02, p=0.9$ & $0.11, p=0.6$ & $0.15, p=0.5$ & $-0.40, p=0.04$ \\
\hline LS BMC $(g)$ & $-0.01, p=1.0$ & $-0.11, p=0.6$ & $-0.12, p=0.5$ & $-0.20, p=0.3$ & $-0.02, p=0.9$ & $-0.01, p=0.9$ & $-0.35, p=0.08$ \\
\hline LS BMAD & $0.25, p=0.2$ & $0.19, p=0.3$ & $0.20, p=0.3$ & $0.14, p=0.5$ & $0.28, p=0.2$ & $0.16, p=0.5$ & $-0.38, p=0.06$ \\
\hline FN BMD $\left(\mathrm{g} / \mathrm{cm}^{2}\right)$ & $-0.05, p=0.8$ & $-0.12, p=0.5$ & $-0.11, p=0.6$ & $-0.17, p=0.4$ & $0.04, p=0.8$ & $-0.02, p=0.9$ & $-0.44, p=0.03$ \\
\hline FN BMD SDS & $-0.23, p=0.2$ & $-0.27, p=0.2$ & $-0.20, p=0.3$ & $-0.30, p=0.1$ & $-0.14, p=0.5$ & $-0.21, p=0.3$ & $-0.40, p=0.05$ \\
\hline FN BMC $(\mathrm{g})$ & $-0.01, p=1.0$ & $-0.07, p=0.7$ & $-0.17, p=0.4$ & $-0.15, p=0.5$ & $0.05, p=0.8$ & $0.03, p=0.9$ & $-0.43, p=0.03$ \\
\hline App BV/TV & $-0.30, p=0.1$ & $-0.28, p=0.2$ & $-0.20, p=0.3$ & $-0.29, p=0.1$ & $-0.14, p=0.5$ & $-0.07, p=0.7$ & $-0.29, p=0.1$ \\
\hline App TbN $\left(\mathrm{mm}^{-1}\right)$ & $-0.40, p=0.04$ & $-0.26, p=0.2$ & $-0.29, p=0.1$ & $-0.27, p=0.2$ & $-0.03, p=0.9$ & $0.07, p=0.7$ & $-0.28, p=0.2$ \\
\hline
\end{tabular}

This article is protected by copyright. All rights reserved. 


\begin{tabular}{llllllll}
\hline App ThSp $(\mathrm{mm})$ & $0.37, p=0.06$ & $0.32, p=0.1$ & $0.31, p=0.1$ & $0.35, p=0.1$ & $0.12, p=0.6$ & $0.00, p=0.9$ & $0.36, p=0.1$ \\
App ThTh $(\mathrm{mm})$ & $0.01, p=0.9$ & $-0.03, p=0.9$ & $0.09, p=0.6$ & $-0.02, p=0.9$ & $-0.02, p=0.9$ & $-0.02, p=0.9$ & $-0.03, p=0.9$ \\
\end{tabular}

Table 3 Correlations between measures of bone health and adiposity as assessed by DXA and MRI in the whole cohort of cases of T1DM and healthy women. CSA- cross-sectional area of adipose tissue; SCAT - subcutaneous adipose tissue; VAT- visceral adipose tissue; TAT - total adipose tissue; TB FM- total body fat mass; TB BMC; total body bone mineral content; TB BMD; total body bone mineral density; LS BMC- lumbar spine bone mineral content; LS BMD- lumbar spine bone mineral density; LS BMAD- lumbar spine bone mineral apparent density; FN-BMC; femoral neck bone mineral content; FN-BMD; femoral neck bone mineral density; AppBV/TV - apparent bone volume/total volume; AppTb.N - apparent trabecular number; AppTbSp - apparent trabecular separation; AppTbTh - apparent trabecular thickness; BMAbone marrow adiposity.

This article is protected by copyright. All rights reserved. 
Fig.1

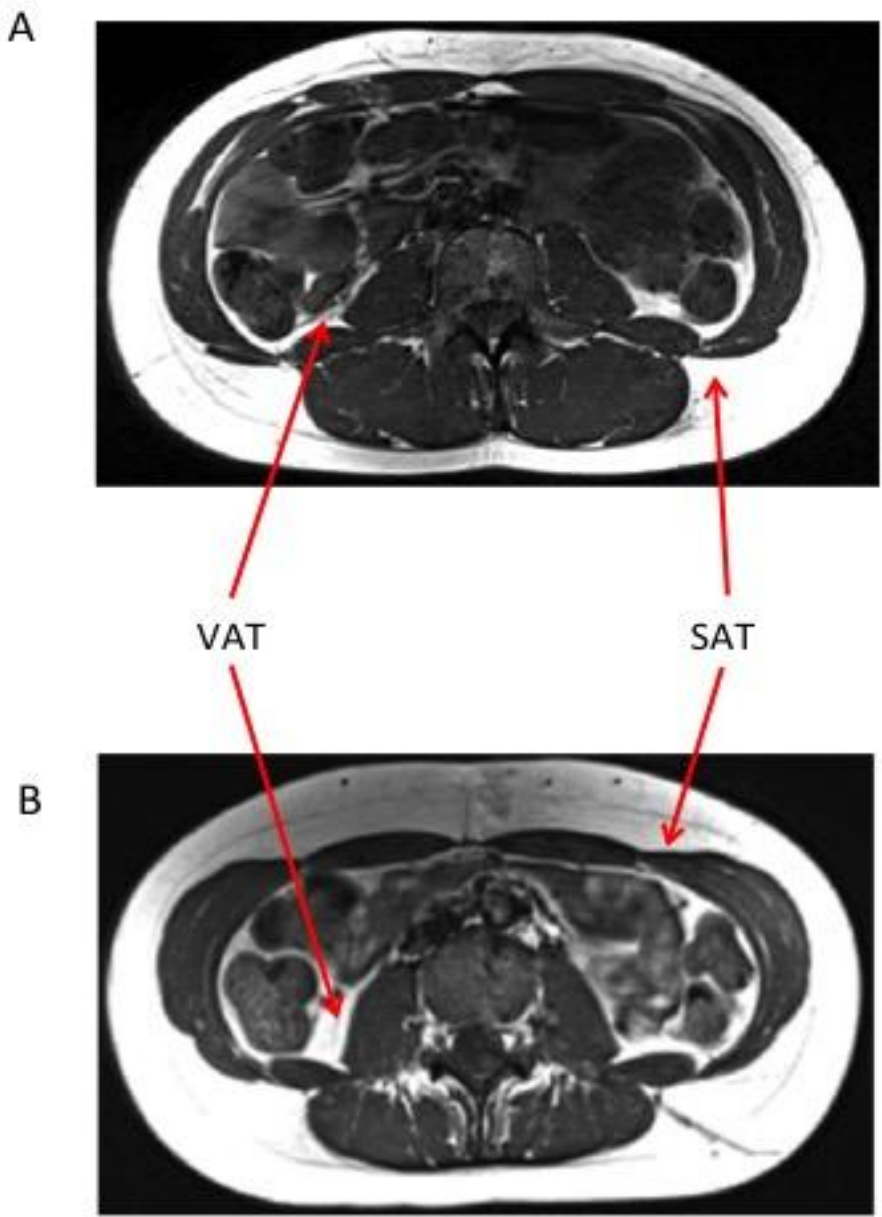

This article is protected by copyright. All rights reserved. 
Fig.2
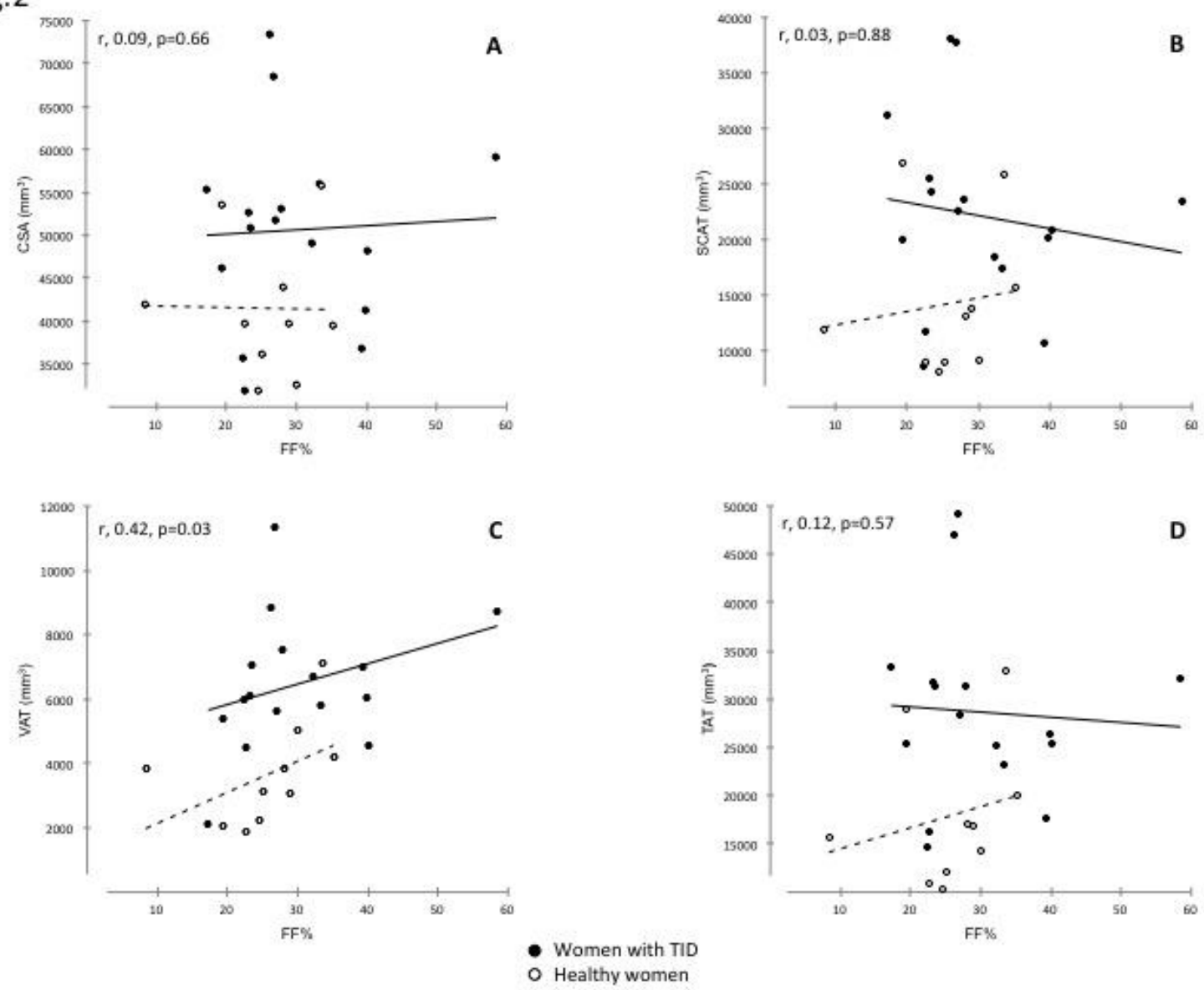

This article is protected by copyright. All rights reserved. 
Fig. 3
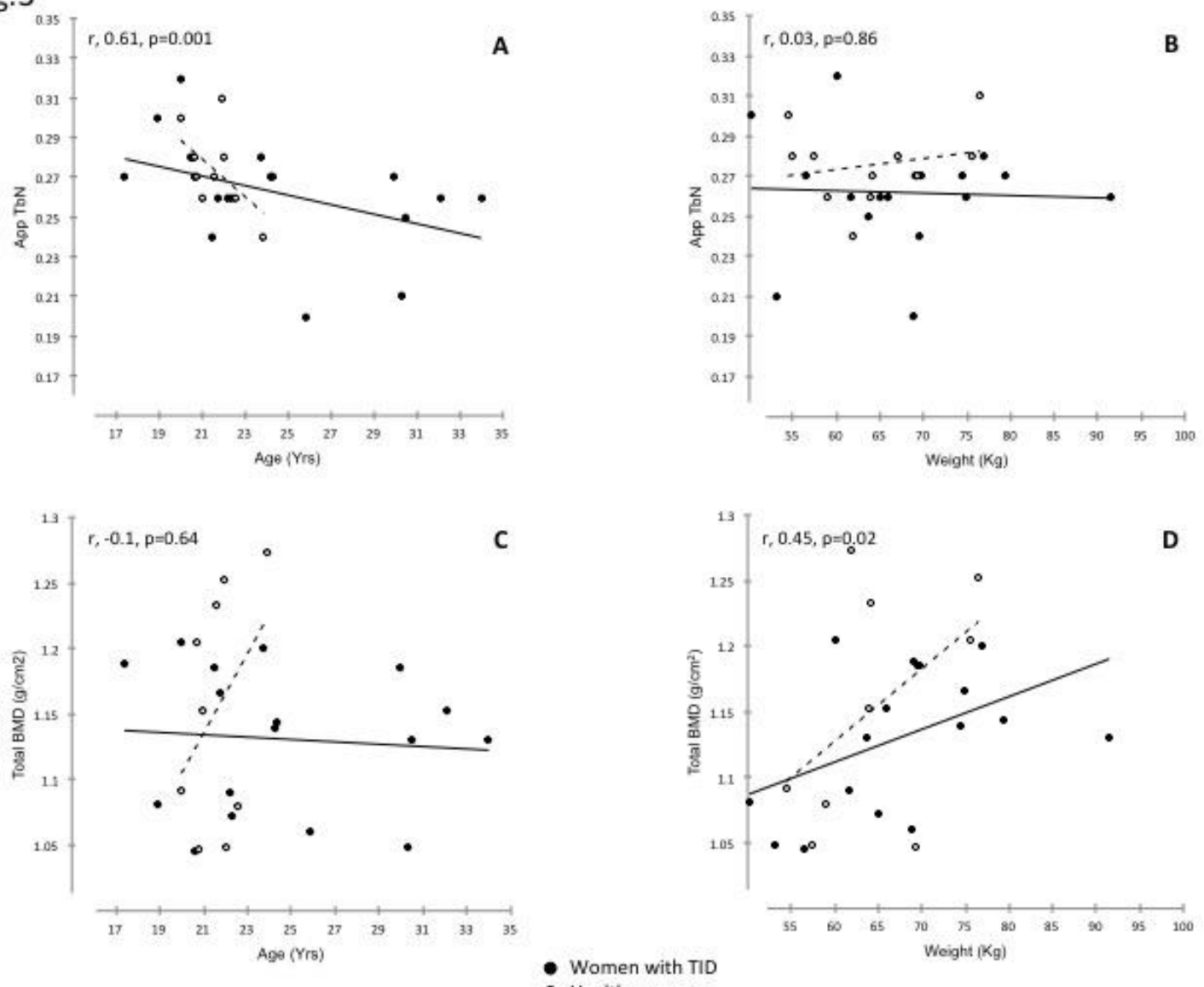

- Healthy women

This article is protected by copyright. All rights reserved. 
Figure 4

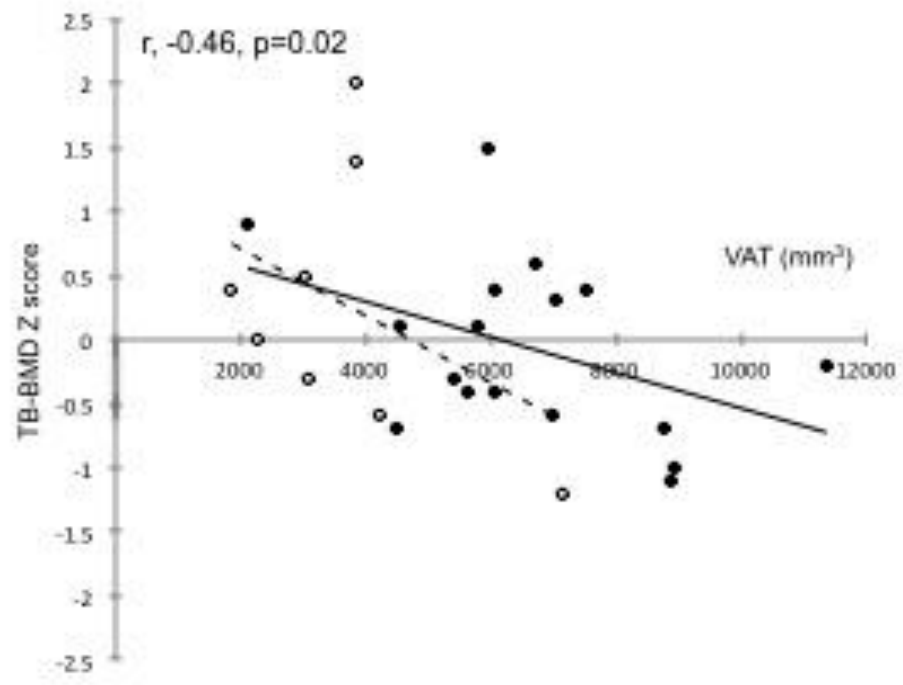

- Women with TID

- Healthy women

This article is protected by copyright. All rights reserved. 